\title{
Pressure gradient in the eye
}

\author{
Ayse Idil Cakmak ${ }^{1 *}$ and Ahmet Ozer ${ }^{2}$ \\ ${ }^{1}$ Hatay Mustafa Kemal University Tayfur Ata Sokmen Medical Faculty, Dept of Ophthalmology Hatay, Turkey \\ ${ }^{2}$ Eskisehir Osmangazi University Medical Faculty, Dept of Ophthalmology Eskisehir, Turkey
}

\section{Dear Editor,}

It is a proven fact that the pressure at the base of the fluid is greater than that which is at the top, due to the weight of the fluid itself [1]. The eyeball is a spherical object, filled with vitreous humor, a fluid with a certain density. For this reason, hydrostatic pressure on the retinal surface would differ, if it was able to be measured. Although the pressure within the eyeball depends primarily on the amount of aqueous humor being continuously produced and drained away, vitreous humor may also contribute, even a little, to this pressure. It could be a noteworthy difference in the intraocular pressure (IOP) due to the pressure gradient induced by the weight of vitreous, which is a hydrostatic pressure.

For this reason, it is very likely that, the pressure on the lower part of the eye would be more than it is on the upper, due to the hydrostatic pressure of vitreus. Ozer et al have made theoretical calculations to find pressure gradient produced by the weight of vitreous. According to this study, theoretically, different pressure gradients were found on various parts of retina, and this difference was about $1.5 \mathrm{mmHg}$ among different retinal points [2].

It may also be possible to assume that, this difference in pressure gradient has an effect upon retinal vessels. Each blood vessel in the retina, has both an internal pressure and an external pressure (intraocular pressure). The difference between them is called, the transmural pressure. Based on the Laplace law, which states a relationship between the radius and transmural pressure of the vessels, the smaller the radius, the larger the pressure it can withstand [3]. So, if a vessel withstands a huge amount of pressure, it should have a smaller radius.

Applying this law on the eyeball, radii of retinal blood vessels should differ from each other in different parts of retina because of the difference in hydrostatic pressure gradients of vitreus. According to this theory, because of the weight of vitreous humor, there should be more hydrostatic pressure in the lower aspect of the eyeball compared with the upper, which should cause the vessels' diameter in the inferior retinal region being smaller than that of the superior ones.

This aforementioned theory is supported by the findings of the study of Jonas and associates, who have found the diameter of the retinal vessels significantly smaller in eyes of glaucoma comparing with normal eyes. The differences have been found to be more marked on the arteries and inferior temporal veins [4].

Copyright: $(2018$ Cakmak AI. This is an open-access article distributed under the terms of the Creative Commons Attribution License, which permits unrestricted use, distribution, and reproduction in any medium, provided the original author and source are credited.
Crichton et al have reported that patients with asymmetric visual field defects had a mean IOP difference between the two eyes, which accounted for either greater than or equal to $1 \mathrm{mmHg}$ [5]. Hence, if even $1 \mathrm{mmHg}$ increase in IOP in one eye can exceed the limit of required threshold for any visual field damage to occur, then the same thing may very well be true for two different regions of the retina in the same eye. In patients with glaucoma, visual field defects appear initially in the superior quadrants, indicating that ganglion cells are more damaged in the inferior retinal region [6-8]. If this proves to be the case, then the pressure gradient between superior and inferior retinal regions may lead to different defects in the superior and inferior visual fields.

Because of gravity, IOP gradients would change on different parts of retina. The vessels of the lower parts of the eye would be more vulnerable to this extra pressure induced by vitreous weight by posture. This extra pressure may do cause a poor perfusion in the lower aspect's retina. This would explain the cause of asymmetrical visual field defects due to damages of ganglion cells under different amounts of pressure depending on the posture, or other individual habits. So finally, for future studies, taking this pressure gradient into account, may help us to elucidate the asymmetric visual field changes which are unexplained.

\section{References}

1. Bond T, Hughes C (2014) IGCSE Physics Challenging Drill Solutions (Yellowreef) 72

2. Ozer A, Esen F, Esen H, Yurdakul S (2002) Intraocular Pressure Gradient Due to Vitreous Weight and Its Possible Effects Upon Retinal Vessels. TKlin J Med Res 20: 78-83.

3. Damask AC (1978) Medical physics. Volume 1. Physiological physics, External probes New York: Academic Pics Inc: 11-12.

4. Jonas J, Nguyen XN, Naumann GO (1989) Parapapillary retinal vessel diameter in normal and glaucoma eyes. I. Morphometric data. Invest Ophthalmol Vis Sci 30: 15991603. [Crossref]

5. Crichton A, Drance SM (1989) Unequal intraocular pressure and its relations to asymmetric visual field defects in low tension glaucoma. Ophthalmology 96: 13121314. [Crossref]

6. Hart WM Jr, Becker B (1982) The onset and evolution of glaucomatous visual field defects. Ophthalmology 89: 268-279. [Crossref ]

7. Araie M, Kitazawa M, Koseki N (1997) Intraocular pressure and central visual field of normal tension glaucoma. Br J Ophthalmol 81: 852-856. [Crossref]

8. Henson DB, Spry PG, Spencer IC, Sparrow JM (1998) Variability in glaucomatous visual fields: implications for shared care schemes. Ophthalmic Physiol Opt 18: 120125. [Crossref]

${ }^{*}$ Correspondence to: Ayse Idil Cakmak, Hatay Mustafa Kemal University Tayfur Ata Sokmen Medical Faculty, Department of Ophthalmology Hatay, Turkey, Tel: 00905068865944; E-mail: idilayse@yahoo.com

Received: October 01, 2018; Accepted: October 11, 2018; Published: October 15, 2018 